\title{
Definition of a new unbiased gonad index for aquatic invertebrates and fish: its application to the sea urchin Paracentrotus lividus
}

\author{
Rosana Ouréns $^{1, *}$, Juan Freire ${ }^{1,2}$, Luis Fernández ${ }^{1}$ \\ ${ }^{1}$ Grupo de Recursos Marinos y Pesquerías, Facultad de Ciencias, Universidad de A Coruña, Rúa da Fraga 10, \\ 15008 A Coruña, Spain \\ ${ }^{2}$ Present address: Barrabés Next, C. Serrano 16-1, 28001 Madrid, Spain
}

\begin{abstract}
The gonad index is a tool widely used for studying the reproductive cycle of a large range of species, although its validity has been questioned in various scientific studies. One of the main criticisms is the assumption of an isometric relationship between gonad size and body size, a premise that has not been verified in most of the cases in which it has been applied. In this study we define the standardized gonad index (SGI), an indicator of the reproductive cycle based on the differences between the observed and expected weights of the gonads for an individual of a given size. Unlike other gonad indices, the SGI takes into account the possible allometric gonadal growth and is suitable for comparative analyses with samples composed of individuals of different sizes as well as samples that have been collected in different areas or at different times of the year. In order to show its advantages over other gonad indices, we applied this new index to 2 sea urchin Paracentrotus lividus populations and compared the results with those of the gonad index most frequently used for these organisms.
\end{abstract}

KEY WORDS: Gonad index $\cdot$ Reproduction $\cdot$ Allometry $\cdot$ Size effect $\cdot$ Residuals $\cdot$ Paracentrotus lividus

Resale or republication not permitted without written consent of the publisher

\section{INTRODUCTION}

The gonad index (GI) is a ratio between the gonad and body size that is used widely for describing and analysing the reproductive cycle of marine species. The basic principle is that temporal variations in the gonad size reflect the phases of the reproductive cycle (Giese \& Pearse 1974, Erickson et al. 1985). Thus, the accumulation of nutrients in the gonad before gametogenesis, as well as the production of gametes, leads to gonadal growth and therefore to a high GI. When the gametes are released, the gonad decreases in size and the GI is low. The gonad then accumulates nutrients once again for the following gametogenesis, and the GI gradually increases (Walker et al. 2007).
An important drawback of the GI method is that it provides little indication as to what is occurring within the gonads. Thus, when nutritive tissue within the gonads is used to synthesize the gametes, the index may remain the same despite an increase in the gametogenesis (Giese \& Pearse 1974, Nichols \& Barker 1984).

Another problem associated with the GI is that causes other than reproduction can also lead to changes in gonad reserves, resulting in occasional peaks in the GI that could be interpreted incorrectly as successive spawning episodes (Byrne 1990, King et al. 1994, Sellem \& Guillou 2007). For instance, such peaks appeared in Sphaerechinus granularis off south Brittany (France) when the seawater temperature was abnormally low, suggesting that nutrient 
resources from the gonad had been used (Guillou \& Michel 1993). Similarly, Lozano et al. (1995) reported a drop in the GI of Paracentrotus lividus after a period of strong storms, which might have led to a decrease in nutritive storage.

In addition, it is particularly complicated to identify reproductive patterns based on the GI in populations that show partial spawning or in individuals which could be at different developmental stages. In these cases the decrease in the index during the spawning period may not be evident for the entire population (Seward 2002, Mercier \& Hamel 2009). Due to these limitations, various authors have criticized the use of the GI in reproductive studies and have suggested using more precise techniques, such as histology (Nichols et al. 1985, Lozano et al. 1995, Seward 2002).

Despite these disadvantages, the GI is an intuitive index of the reproductive process that is easy to estimate, while histology, although more exact, is a costly technique that requires additional resources, time and experience. Furthermore, in species whose commercial value resides in the gonads, such as echinoids, the GI has 2 immediate applications useful for fisheries. First, this parameter allows the spawning period to be identified approximately, which provides information that can be used to guide fishing regulations such as the establishment of closed seasons. Second, the GI can be used to estimate the expected commercial yield of a stock and its temporal and spatial variation. This information allows rotations to be planned as well as the seasonality of the fishing operations, and thus maximize fishing profits.

A wide variety of measurements can be used to express the gonad and body sizes, including dry and wet weights or volumes. Linear dimensions are also used to represent body size, such as the body length or diameter (see revisions of Gurney \& Mundy 2004, González-Irusta 2009, Ebert et al. 2010, Ouréns et al. 2011). The measurements chosen to represent both the sizes and the relationship established between them, which may or may not include some exponent in the ratio, give rise to a variety of GIs. As a result, it is frequently not possible to compare absolute values between studies, although it is possible to contrast trends.

The gonosomatic index is the most common GI in the literature, and it represents the percentage of the gonad wet weight (GWW) in relation to the individual's wet weight (IWW). This expression is based on the premise that the gonads appear during embryogenesis, and therefore the straight line that relates the GWW and the IWW passes through the origin. Furthermore, this index assumes the relationship between the 2 measures is isometric, meaning that both the gonad and body weight increase at the same rate. Consequently, we will refer to this index as the linear gonad index (LGI):

$$
\mathrm{LGI}=\frac{\mathrm{GWW}}{\mathrm{IWW}} \cdot 100
$$

Most previous studies that use the LGI assume that these statements are true without first verifying them, even though they have been shown to be false for several marine species (Russell 1998, Stoltz et al. 2005, Nanri et al. 2011). In these cases, the LGI, or any other GI that assumes isometric gonad growth, should not be used to compare individuals with different sizes, since it could lead to erroneous conclusions about their reproductive cycle (Devlaming et al. 1982, Erickson et al. 1985, Bonardelli and Himmelman 1995, Somarakis et al. 2004).

The purpose of the present study was to develop and test an index of the reproductive cycle that is easy to estimate and interpret and that is not biased on the allometric growth of the gonad. A standardized gonad index (SGI) would allow us to compare samples collected in different areas and different seasons as well as samples composed of differentsized individuals. As a case study, we applied this new GI to 2 populations of sea urchins Paracentrotus lividus and compared it with the GI most commonly employed for these organisms (the LGI). However, the SGI is a general index that can be used in other aquatic invertebrates or fish.

\section{MATERIALS AND METHODS}

This work was carried out as part of a wider study on the population and reproductive dynamics of the sea urchin Paracentrotus lividus and the influence of certain environmental and demographic factors on this species. In this paper we present the data from the Queiruga fishing ground (Porto do Son, $42^{\circ} 39.6^{\prime} \mathrm{N} 9^{\circ} 04.2^{\prime} \mathrm{W}$ ) at $12 \mathrm{~m}$ depth in a low-density area $\left(0.53 \pm 0.01\right.$ individuals $\mathrm{m}^{-2}$, mean $\left.\pm \mathrm{SE}\right)$, and the data from the Ardeleiro fishing ground (Lira, $42^{\circ} 47.8^{\prime} \mathrm{N} 9^{\circ} 8.94^{\prime} \mathrm{W}$ ) at $4 \mathrm{~m}$ depth in an area with dense patches of sea urchins $(95.78 \pm 4.07$ individuals $\mathrm{m}^{-2}$ ). These sampling sites were chosen because they showed notable variations between the new GI defined in this study and the LGI.

The present study is based on data from a total of 855 sea urchins collected monthly from June 2006 to May 2008. They had diameters between 41.3 and $90.0 \mathrm{~mm}$ (measured as the maximum size of the 
equatorial plane of the body without spines), the size range at which at least $95 \%$ of the population is sexually mature (R. Ouréns et al. unpubl. data).

The diameter of the sea urchins was measured with a vernier caliper $( \pm 0.1 \mathrm{~mm})$. After obtaining the wet weight $( \pm 0.01 \mathrm{~g})$ of each individual, the gonads were extracted and placed on absorbent paper for a few minutes to eliminate excess water. The gonads were then weighed (wet weight $\pm 0.001 \mathrm{~g}$ ) and placed in an oven at $60^{\circ} \mathrm{C}$ for $48 \mathrm{~h}$, until a constant weight corresponding to the dry weight $( \pm 0.001 \mathrm{~g})$ was obtained.

The first step in estimating the SGI was to determine the mathematical expression that best represented the relationship between the 2 variables to be associated: the gonad dry weight (GDW) and the diameter $(D)$. We chose to use these variables because they do not depend on the amount of coelomic fluid and water content of the tissues. Sea urchins lose water continuously when they are removed in the field and this process varies between individuals (Régis 1978). Therefore, standardizing the measurement conditions for wet weight is difficult and we consider that it is a highly variable measure for estimating the SGI (Mercier \& Hamel 2009). In contrast, the diameter shows high repeatability among measurements and is therefore a more precise variable.

The following potential regressions were applied to the data set of each population:

$$
\mathrm{GDW}=a \cdot D^{b}
$$

and

$$
\mathrm{GDW}=a \cdot(D-C)^{b}
$$

where $a, b$ and $c$ are the parameters to be estimated. Unlike the model in Eq. (2), Eq. (3) incorporates the possibility that the gonads start to develop at a body size different from 0 (parameter $c$ ). In our case we assume that $c$ is $27.9 \mathrm{~mm}$, the size at which $50 \%$ of the population has macroscopically visible gonads (R. Ouréns et al. unpubl. data). This potential model was proposed by Ebert \& Russell (1994) and applied by Russell (1998) and Ebert et al. (2010).

The variables, GDW and $D$, were log transformed to linearize their relationship and approximate normality. The fit of the linear models was compared graphically and also using Akaike's information criterion (AIC, Akaike 1974) at each sampling station. All the statistical analyses were carried out using the free software R (v.2.14.1, R Development Core Team 2012).

We then defined the SGI as the residuals of the linear model finally chosen:

$$
\mathrm{SGI}_{i}=\log \mathrm{GDW}_{i}-\overline{\log \mathrm{GDW}_{i}}
$$

where $\log \mathrm{GDW}_{i}$ represents the logarithm of the GDW observed in the $i$ th individual, and ${\overline{\log \mathrm{GDW}_{i}}}$ is the predicted value from the regression for an individual of this body size.

This index is centered on zero, and individuals with gonads larger than those corresponding to a sea urchin of a given size will have positive SGIs. In contrast, individuals with less developed gonads will have negative SGIs.

To determine whether the SGI is independent of the body diameter at each sampling site, we carried out a linear regression between the 2 variables using linear mixed models (package 'nlme' in the R program, Pinheiro \& Bates 2000). We expect that an individual of a given size will have a high SGI in the months of maximum gonadal development and low SGI after the spawning season. Therefore, we included the effect of month as a random variable in the model. A correction for heteroscedasticity was applied by allowing a different variance for each month (function 'varIdent' in R), and when temporal correlation was observed, we corrected it using a first-order auto-regressive process in the error structure. Linear mixed models were also carried out between the LGI and $D$.

We used graphical methods (e.g. residual diagnostic plots, the observed trends augmented with the fitted trend plots) to assess the adequacy of the final fitted models (Supplement 1 at www.int-res.com/ articles/suppl/b017p145_supp.pdf). To facilitate estimating the SGI, the R code used for the analyses is available as an electronic supplement (Supplement 2 at www.int-res.com/articles/suppl/b017p145_supp/).

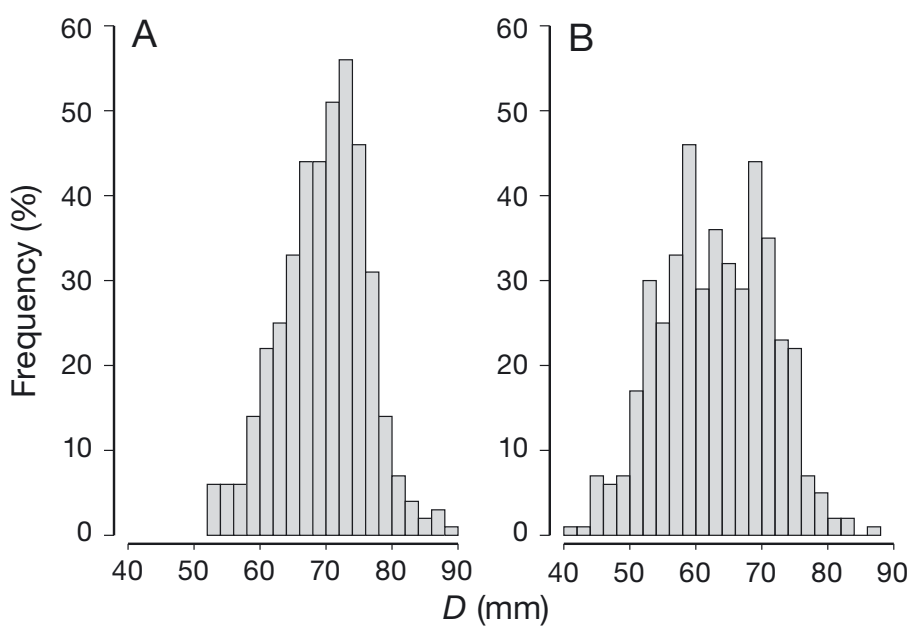

Fig. 1. Paracentrotus lividus. Size frequency distribution of sea urchins in the 2 study populations (A) Queiruga and (B) Ardeleiro. $D$ : test diameter 


\section{RESULTS}

The Kolmogorov-Smirnov test showed that the size distribution of the 2 populations was different $(p<$ 0.01; Fig. 1). The mean size in Queiruga was $6.8 \mathrm{~mm}$ larger than in Ardeleiro (Student's t-test, $\mathrm{p}<0.01$ ), but the variance was larger in the latter population (Barlett's test, $\mathrm{p}<0.01$ ).

The fitted regressions between $\log$ GDW and $\log D$ under the 2 models explored are very similar and the differences were limited to the more extreme sizes, for which the data were limited (Fig. 2). The difference in AIC was lower than 1 unit for the 2 sampling sites (Table 1), and in these cases Burnham \& Anderson (2004) argue that the improvement in the model is not evident. According to this criterion, we chose (Eq. 2) because it is simpler (see 'Discussion').

The 2 sampling sites showed different gonadal growth (Table 1). Parameter $b$ of Eq. (2) was around 3 in Ardeleiro $(b=3.13)$, the expected value in the case of isometry between a 1-dimensional variable (diameter) and a 3-dimensional variable (weight). Therefore, the gonads grew at a similar rate (slightly higher) to the diameter. In contrast, Queiruga showed allometric gonadal growth, since parameter $b$ was 1.84 , and therefore the sea urchin gonads increased in size more slowly than the diameter.

The fitted lines between $\log$ GDW and $\log D$ represent the annual average ratio. The wide dispersion observed around the fitted lines partly reflects the monthly variations in log GDW within a year (Fig. 2). Seasonality in the SGI (Fig. 3), which causes a large part of the residual variability in the GDW, will not be analyzed in detail here.

Finally, the SGI was independent of the diameter of the individuals at the 2 sampling sites (Fig. 4, Table 2). In contrast, the LGI behaved differently in the 2 populations. While the LGI decreased significantly with sea urchin size in Queiruga $(p<0.01)$, the LGI in Ardeleiro followed the opposite trend, increasing slightly for the biggest sea urchins $(p=$ $0.01)$.

\section{DISCUSSION}

The fit of the 2 models used to describe the relationship between $\log$ GDW and $\log D$ was very similar.

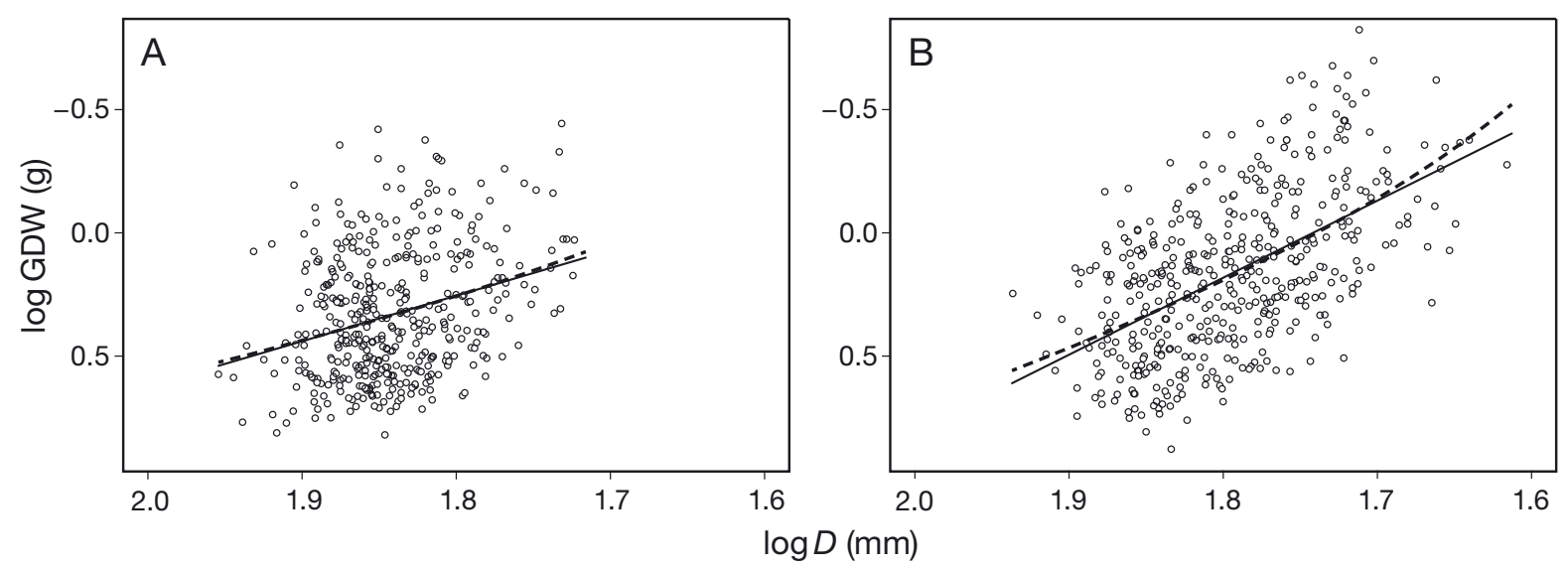

Fig. 2. Paracentrotus lividus. Linear regressions between log-transformed gonad dry weight (GDW) and test diameter (D) of the sea urchins in (A) Queiruga and (B) Ardeleiro showing predictions from log-transformed Eq. (2) (solid line) and logtransformed Eq. (3) (dashed tline)

Table 1. Paracentrotus lividus. Linear regressions between the log-transformed gonad dry weight (GDW) and diameter ( $D$ ) of the sea urchins in the fishing grounds of Queiruga and Ardeleiro under 2 model scenarios determined with Eqs. (2) \& (3). Eq. (3) assumes that the parameter $c$ is $27.9 \mathrm{~mm}$. The size range of the individuals studied and the sample size (n) are also shown. SE: standard error associated with the estimates of each parameter. AIC: Akaike information criterion value associated with each equation

\begin{tabular}{|c|c|c|c|c|c|c|c|c|c|c|c|c|}
\hline \multirow[t]{2}{*}{ Location } & \multirow[t]{2}{*}{$\mathrm{n}$} & \multirow{2}{*}{$\begin{array}{c}D \\
(\mathrm{~mm})\end{array}$} & \multicolumn{5}{|c|}{$\log (\mathrm{GDW})=\log a+b \cdot \log (D)$} & \multicolumn{5}{|c|}{$\log (\mathrm{GDW})=\log a+b \cdot \log (D-27.9)$} \\
\hline & & & $\log a$ & $\mathrm{SE}$ & $b$ & $\mathrm{SE}$ & $\mathrm{AIC}$ & $\log a$ & $\mathrm{SE}$ & $b$ & SE & $\mathrm{AIC}$ \\
\hline Queiruga & 415 & $52.9-90.0$ & -3.062 & 0.545 & 1.843 & 0.296 & 27.67 & -1.431 & 0.279 & 1.091 & 0.173 & 26.59 \\
\hline Ardeleiro & 440 & $41.3-86.4$ & -5.443 & 0.401 & 3.125 & 0.223 & 97.28 & -2.376 & 0.182 & 1.660 & 0.119 & 97.48 \\
\hline
\end{tabular}




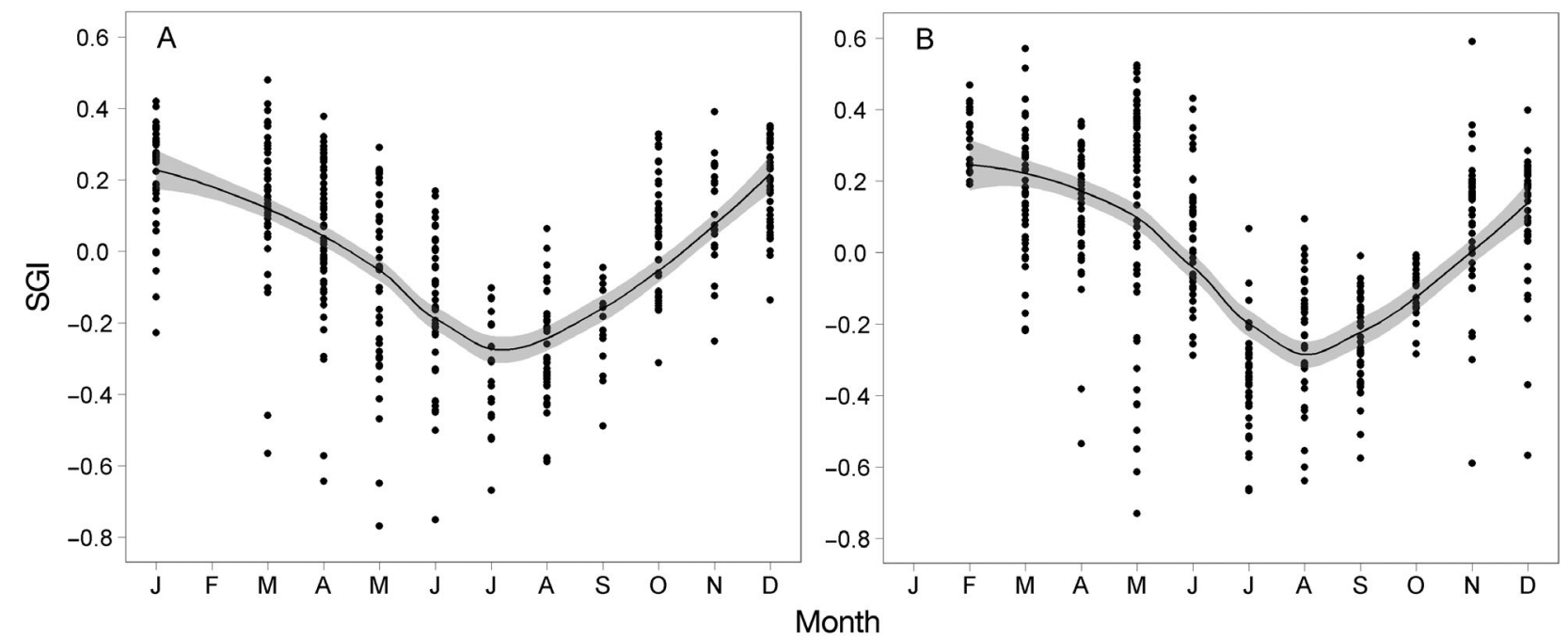

Fig. 3. Paracentrotus lividus. Temporal pattern of the standardized gonad index (SGI) in (A) Queiruga and (B) Ardeleiro. We added a smoothed curve (solid line) and SE (grey shading). The smooth was calculated by local polynomial regressions
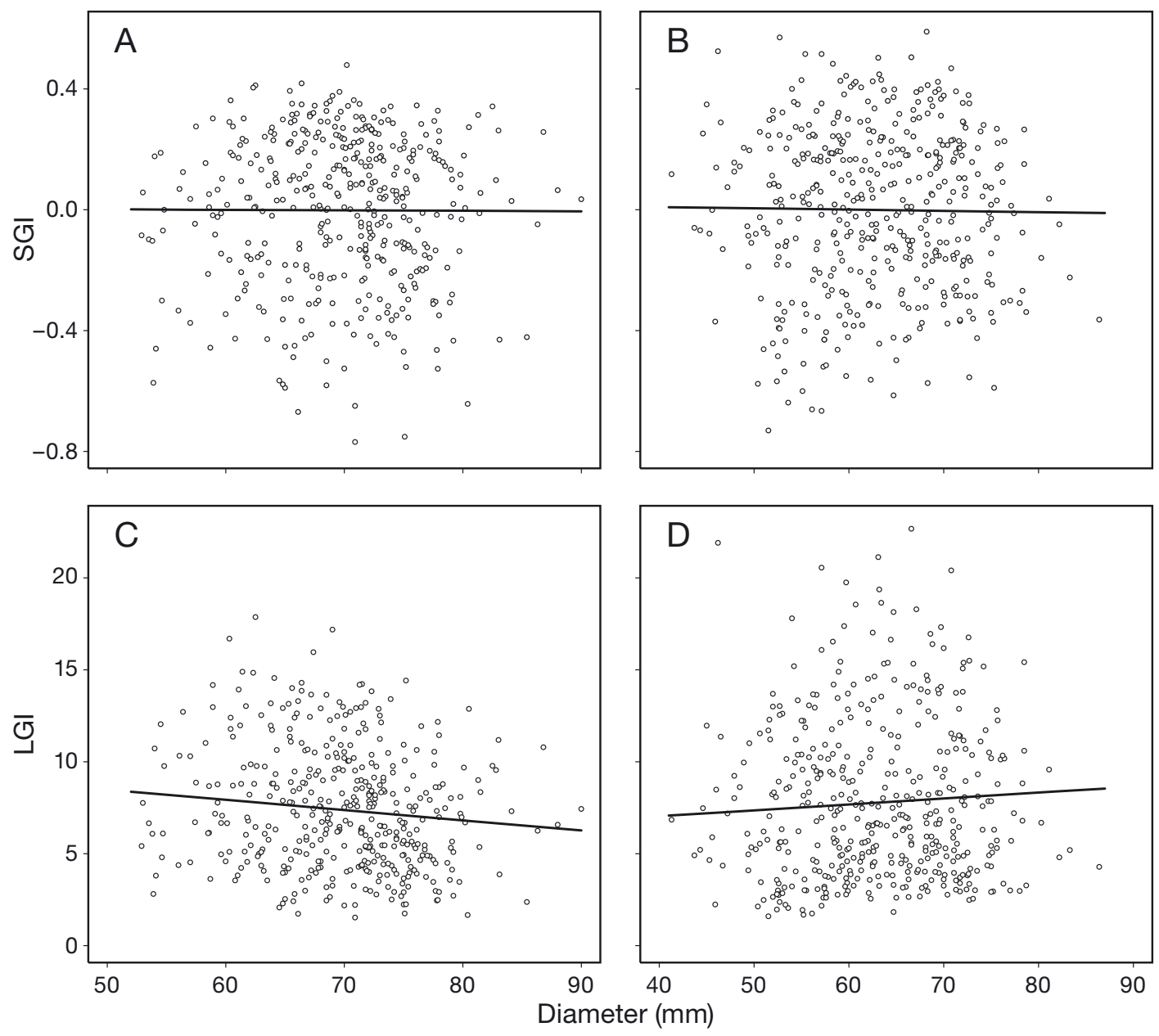

Fig. 4. Paracentrotus lividus. The relationship between the standardized gonad index (SGI) and the linear gonad index (LGI) and test diameter in $(A, C)$ Queiruga and $(B, D)$ Ardeleiro showing observed values $(O)$ and predicted values (black lines) from the linear mixed models 
Table 2. Paracentrotus lividus. Linear regressions between the gonad indices (standardized, SGI, and linear, LGI) and the diameter of the sea urchins in the fishing grounds of Queiruga and Ardeleiro. The mean and the standard errors (SE) of the parameters estimated by the fixed structure of the mixed models are shown. $d^{2}$ : monthly variance experienced by the intercept of the line, estimated by the random structure of the model; $\sigma^{2}$ : residual variance

\begin{tabular}{|c|c|c|c|c|c|c|c|c|}
\hline & \multicolumn{4}{|c|}{ Queiruga- } & \multicolumn{4}{|c|}{ Ardeleiro } \\
\hline & Estimate & SE & $t$ & $\mathrm{p}$ & Estimate & SE & $t$ & $\mathrm{p}$ \\
\hline \multicolumn{9}{|l|}{ SGI } \\
\hline Intercept & $1.05 \times 10^{-2}$ & 0.086 & 0.12 & 0.90 & 0.03 & 0.082 & 0.31 & 0.76 \\
\hline Slope & $1.75 \times 10^{-4}$ & 0.001 & -0.17 & 0.87 & $-4.16 \times 10^{-4}$ & 0.001 & -0.39 & 0.70 \\
\hline $\mathrm{d}^{2}$ & 0.05 & & & & 0.04 & & & \\
\hline$\sigma^{2}$ & 0.02 & & & & 0.01 & & & \\
\hline \multicolumn{9}{|l|}{ LGI } \\
\hline Intercept & 11.25 & 1.109 & 10.14 & $<0.01$ & 5.77 & 1.078 & 5.35 & $<0.01$ \\
\hline Slope & -0.06 & 0.014 & -4.02 & $<0.01$ & 0.03 & 0.012 & 2.68 & 0.01 \\
\hline $\mathrm{d}^{2}$ & 12.34 & & & & 5.88 & & & \\
\hline$\sigma^{2}$ & 7.24 & & & & 5.01 & & & \\
\hline
\end{tabular}

The difference between the 2 equations is at the point where they begin (parameter $c$ ), and therefore the fit of the 2 lines may vary for small-sized individuals. However, these relationships are used to analyze the reproductive dynamics, and they should be restricted to mature individuals. As a result, the simplest model (Eq. 2) is perfectly valid for estimating biometric relationships in our samples, which were composed of individuals with diameters larger than $41.3 \mathrm{~mm}$.

To apply (Eq. 3) to our data, parameter $c$ was set at the size at which individuals reach sexual maturity (test diameter $27.9 \mathrm{~mm}$ ). Russell (1998) used the same criterion and specified a value for $c$ equal to $20 \mathrm{~mm}$ in Strongylocentrotus droebachiensis based on results obtained in previous studies (Munk 1992, Harris et al. 1994). However, Ebert et al. (2010) estimated parameter $c$ by employing the following logarithmic equation:

$$
\ln \mathrm{GWW}=a+b \cdot \ln (D-c)
$$

To avoid the computational errors produced when a logarithm of a negative number is estimated, they had to assume that $c$ was less than any of the diameters in their study. In that case, $c$ had to be less than $1 \mathrm{~cm}$. This procedure could not be carried out in our study since the sample was exclusively composed of mature individuals, and thus it was not possible to estimate the body size at which the gonads begin to develop. Therefore, using Eq. (3) requires additional biological information or unrealistic statistical assumptions, which is a further motive for not using it in samples composed of mature individuals.

In accordance with previous studies carried out on various species (Gonor 1972, Roff 1983, Stoltz et al.
2005, Nanri et al. 2011), the gonads of Paracentrotus lividus can grow at a different rate than its body, and this process may vary between populations. While in Ardeleiro the gonads increased in size at the same rate as the diameter, the gonadal growth in the population of Queiruga was much slower. This different physiological response may have been driven by the different conditions that the sea urchins were subject to at the 2 sampling sites. The sea urchins that inhabit the Ardeleiro fishing ground are exposed to high wave action, and sea urchins may favor reproduction over somatic growth under stressful situations. Our results are similar to those obtained by Turon et al. (1995) in NE Spain, who detected higher somatic growth in habitats characterized by low wave exposure. Similar to our study, the energy invested in reproduction followed the reverse pattern, and gonad production was higher in a changing habitat subjected to strong wave action (Lozano et al. 1995). This explanation may also account for the average $D$ of the population in Queiruga being (mean $\pm \mathrm{SE}$ ) $69.8 \pm$ $0.3 \mathrm{~mm}$, while in Ardeleiro it was only $63.0 \pm 0.4 \mathrm{~mm}$.

Given that gonad growth may be allometric, using the LGI to represent the reproductive cycle of Paracentrotus lividus introduces bias. Furthermore, the level of allometry varies between sites, so assuming a constant error for each size class is not possible. Thus, the sea urchins collected in Queiruga showed negative allometric growth of the gonad, and therefore the LGI decreased as the size of the sea urchins increased. In contrast, the slight positive allometry shown by the sea urchins from Ardeleiro $(b=3.13)$ led to a gradual increase in the LGI with the size of the individuals. Consequently, this index is not appropriate for comparative analyses between samples with individuals of different sizes or collected at different sites.

Ebert et al. (2010), aware of the problems associated with most GIs described in the literature, suggested using the GWW estimated with Eq. (5) as an indicator of the reproductive cycle. This method takes into account the possible development of the gonad to a size other than zero, and its allometric growth with respect to the size of the body. The authors log transformed the GWW and $D$ variables to linearize their relationship and then used analysis of covariance to quantify the monthly variability pres- 
ent in the main pattern. Due to the significant seasonal differences, each sample needed an individual regression, and then the estimated GWWs could only be compared between samples if individuals of an equal size were used.

The SGI proposed in this work also takes into account the possibility that gonadal growth is allometric with respect to the somatic growth. The main advantage of the SGI with respect to the methodology proposed by Ebert et al. (2010) is that it allows comparisons between samples composed by differentsized individuals because it is based on the residuals of the potential relationship between $D$ and the GDW. We realize that variations in the test height:diameter ratio changes the body volume and the capacity for gonad production. However, based on the data in Urgorri et al. (1994), we found that this ratio shows little variation in our species $(0.52 \pm 0.004, \mathrm{n}=104)$, and therefore the variability in the SGI due to differences in the ratio height:diameter is small.

Another advantage associated with the SGI is that to estimate this index establishing a single global relationship between the gonad weight and diameter for the data set is necessary, since one regression for each sample would eliminate any temporal or spatial patterns in the residuals. Consequently, estimating this index in studies with a large number of samples is not as arduous as estimating the index proposed by Ebert et al. (2010).

Nevertheless, the SGI is still a biometric index, and as such it has the limitations that are common to all GIs - it assumes that variations are solely due to reproduction - and it is difficult to interpret populations with partial spawning or in which individuals are at different developmental stages. Therefore, its appropriateness depends on the case studied, the objectives, and the quality of the information required. The SGI could be used as a management tool in many fisheries because highly qualified personnel are not necessary to apply it (as is the case for histological techniques) and the reproductive cycle is determined with sufficient precision for establishing closed seasons.

Acknowledgements. The authors gratefully acknowledge financial support from the Spanish Ministry of Education and Science, and from the European Regional Development Fund (ERDF).

\section{LITERATURE CITED}

Akaike H (1974) A new look at the statistical model identification. IEEE Trans Automat Contr 19:716-723

Bonardelli JC, Himmelman JH (1995) Examination of assumptions critical to body component indices: application to the giant scallop Placopecten magellanicus. Can J Fish Aquat Sci 52:2457-2469

Burnham KP, Anderson DR (2004) Multimodel inference: understanding AIC and BIC in model selection. Sociol Methods Res 33:261-304

Byrne M (1990) Annual reproductive cycles of the commercial sea urchin Paracentrotus lividus from an exposed intertidal and a sheltered subtidal habitat on the west coast of Ireland. Mar Biol 104:275-289

Devlaming V, Grossman G, Chapman F (1982) On the use of the gonosomatic index. Comp Biochem Physiol A 37: 31-39

Ebert TA, Russell MP (1994) Allometry and Model II nonlinear regression. J Theor Biol 168:367-372

Ebert TA, Hernandez JC, Russell MP (2010) Problems of the gonad index and what can be done: analysis of the purple sea urchin Strongylocentrotus purpuratus. Mar Biol 158:47-58

Erickson DL, Hightower JE, Grossman GD (1985) The relative gonactal index: an alternative index for quantification of reproductive condition. Comp Biochem Physiol A 81:117-120

Giese AC, Pearse JS (1974) Introduction: general principle. In: Giese AC, Pearse JS (eds) Reproduction of marine invertebrates, Vol 1. Academic Press, New York, NY, p 1-49

Gonor JJ (1972) Gonad growth in the sea urchin, Strongylocentrotus purpuratus (Stimpson) (echinodermata: Echinoidea) and the assumptions of gonad index methods. J Exp Mar Biol Ecol 10:89-103

González-Irusta JM (2009) Contribución al conocimiento del erizo de mar Paracentrotus lividus (Lamarck, 1816) en el Mar Cantábrico: ciclo gonadal y dinámica de poblaciones. PhD dissertation, Universidad de Cantabria, Santander

Guillou M, Michel C (1993) Reproduction and growth of Sphaerechinus granularis (Echinodermata: Echinoidea) in southern Brittany. J Mar Biol Assoc UK 73:179-192

Gurney LJ, Mundy CM (2004) Reproductive biology: identifying spawning cycles in the genus Haliotis. Tech Rep Ser. Tasmanian Aquaculture and Fisheries Institute, Hobart

Harris LG, Rice B, Nestler EC (1994) Settlement, early survival and growth in a southern Gulf of Maine population of Strongylocentrotus droebachiensis (Müller). In: David B, Guille A, Féral JP, Roux M (eds) Echinoderms through time. Proc 8th Int Echinoderm Conf. AA Balkema, Rotterdam, p 701-706

> King CK, Hoegh-Guldberg O, Byrne M (1994) Reproductive cycle of Centrostephanus rodgersii (Echinoidea), with recommendations for the establishment of a sea urchin fishery in New South Wales. Mar Biol 120:95-106

Lozano J, Galera J, López S, Turon X, Palacín C, Morera G (1995) Biological cycles and recruitment of Paracentrotus lividus (Echinodermata: Echinoidea) in two contrasting habitats. Mar Ecol Prog Ser 122:179-191

Mercier A, Hamel JF (2009) Endogenous and exogenous control of gametogenesis and spawning in echinoderms. Adv Mar Biol 55:1-302

Munk JE (1992) Reproduction and growth of green urchins Strongylocentrotus droebachiensis (Müller) near Kodiak, Alaska. J Shellfish Res 11:245-254

Nanri T, Fukushige M, Ubaldo JP, Kang BJ, Masunari N, Takada Y, Hatakeyama M, Saigusa M (2011) Occurrence 
of abnormal sexual dimorphic structures in the gonochoristic crustacean, Upogebia major (Thalassinidea: Decapoda), inhabiting mud tidal flats in Japan. J Mar Biol Assoc UK 91:1049-1057

Nichols D, Barker MF (1984) A comparative study of reproductive and nutritional periodicities in two populations of Asterias rubens (Echinodermata: Asteroidea) from the English Channel. J Mar Biol Assoc UK 64:471-484

Nichols D, Bishop GM, Sime AAT (1985) Reproductive and nutritional periodicities in populations of the European sea urchin Echinus esculentus (Echinodermata: Echinoidea) from the English Channel. J Mar Biol Assoc UK 65:203-220

Ouréns R, Fernández L, Freire J (2011) Geographic, population, and seasonal patterns in the reproductive parameters of the sea urchin Paracentrotus lividus. Mar Biol 158: 793-804

Pinheiro JC, Bates DM (2000) Mixed-effects models in S and S-PLUS. Springer Verlag, New York, NY

R Development Core Team (2012) R: a language and environment for statistical computing. R Foundation for Statistical Computing, Vienna. www.R-project.org/

Régis MB (1978) Croissance de deux echinoïdes du Golfe de Marseille (Paracentrotus lividus (Lmk) et Arbacia lixula L.): aspects écologiques de la microstructure du squelette et de l'évolution des indices physiologiques. $\mathrm{PhD}$ dissertation, Université d'Aix-Marseille III

Roff DA (1983) An allocation model of growth and reproduction in fish. Can J Fish Aquat Sci 40:1395-1404

Russell MP (1998) Resource allocation plasticity in sea

Editorial responsibility: Christine Paetzold,

Oldendorf/Luhe, Germany urchins: rapid, diet induced, phenotypic changes in the green sea urchin, Strongylocentrotus droebachiensis (Müller). J Exp Mar Biol Ecol 220:1-14

> Sellem F, Guillou M (2007) Reproductive biology of Paracentrotus lividus (Echinodermata: Echinoidea) in two contrasting habitats of northern Tunisia (south-east Mediterranean). J Mar Biol Assoc UK 87:763-767

Seward LCN (2002) The relationship between green sea urchin spawning, spring phytoplankton blooms, and the winter-spring hydrography at selected sites in Maine. MS thesis, University of Maine, Orono, ME

Somarakis S, Ganias K, Tserpes G, Koutsikopoulos C (2004) Ovarian allometry and the use of the gonosomatic index: a case study in the Mediterranean sardine, Sardina pilchardus. Mar Biol 146:181-189

Stoltz JA, Neff BD, Olden JD (2005) Allometric growth and sperm competition in fishes. J Fish Biol 67:470-480

Turon X, Giribet G, López S, Palacín C (1995) Growth and population structure of Paracentrotus lividus (Echinodermata: Echinoidea) in two contrasting habitats. Mar Ecol Prog Ser 122:193-204

Urgorri V, Reboreda P, Troncoso JS (1994) Dispersión, demografía y producción gonadal de una población de Paracentrotus lividus (Lamarck, 1816). Departamento de Biología Animal, Universidad de Santiago de Compostela

Walker CW, Unuma T, Lesser MP (2007) Gametogenesis and reproduction of sea urchins. In: Lawrence JM (ed) Edible sea urchins: biology and ecology, 2nd edn. Dev Aquac Fish Sci, Vol 32. Elsevier Science BV, Amsterdam, p 11-34

Submitted: May 9, 2012; Accepted: September 3, 2012 Proofs received from author(s): October 30, 2012 